\title{
Oral Communicative Competence of Filipino College Students: Levels, Correlates, and Characteristics
}

\author{
Dr. Allan Paul D. Sandigan, LLB \\ Assistant Professor, College of Teacher Education, Bohol Island State University, Philipppines \\ Email: apsandigan@bisu.edu.ph
}

\begin{abstract}
The oral communicative competence of freshman students was determined by their linguistic and sociolinguistic proficiency. This was measured in the way students demonstrated their facility of the English language through their accurate production of sounds (phonetic skill) and in lending more meaning to the utterance through intonation patterns. Convergent skill in oral production and use of grammar, vocabulary, and rhetoric created the impression of oral communicative competence. The facility for oral communication was influenced by social and cultural factors in the home, the environment, and the school. The study had shown that students who had no training or limited training in reading and in classroom interaction developed into less English proficient students. The type of school from which one graduated, the income of parents whose income afforded or deprived exposure of children to English reading materials, and the absence of a highly skilled teacher in communication influenced greatly affected the outcome of a highly skilled communicator. Intervention measures started with a methodical study of the weaknesses of the English Program in the College. The designed program should depart radically from the traditional and remediation approaches but must put meaning into a longitudinal and progressive development of language skills in all year levels in all courses across disciplines. Appropriate and consistent monitoring, evaluation and review ensured the success of the program.
\end{abstract}

Keywords- Communicative Ability, Communicative Competence, Linguistic Competence, Pedagogical Intervention, Sociolinguistic Competence.

\section{INTRODUCTION}

The primary purpose of the current study was to determine the dimensions of oral communicative competence of first semester freshman students at one college in the Philippines. Three objectives emanated from this purpose: (a) What is the level of the students' oral communicative competence, both linguistically and sociolinguistically? (b) What are the correlates of their competence? and (c) What are the characteristics of their competence?

This work is founded upon theoretical work on communicative competence, as propounded by Canale and Swain (1980) and by Bachman (1990). According to Canale and Swain (see also, Canale, 1983), communicative competence consists of four indispensable components: grammatical (also known as linguistic), sociolinguistic, discourse, and strategic competences. Grammatical competence involves knowledge of lexical items and of rules of morphology, syntax, sentencegrammar semantics, and phonology. Sociolinguistic competence is concerned with the knowledge of sociocultural rules of language and discourse. Discourse competence reflects the ability to connect sentences in stretches of discourse and to form meaningful wholes out of series of utterances. Strategic competence refers to the verbal and non-verbal communication strategies that might be called into action to compensate for breakdowns in communication due to performance variables or insufficient competence. For English as an Additional Language (EAL) learners to reach a level of communicative competence, all four components are of critical importance, although the current study targets just the first two.

Bachman (1990) offered a different but largely complementary view of communicative competence based on his work in language assessment. According to him, communicative competence relates language competence, or knowledge of language, to the language user's knowledge structures and the features of the context in which communication takes place. It embraces all aspects of the assessment, the planning, and the execution of a communicative task; it is a cognitive capacity whose components comprise a set of metacognitive processes or strategies, which provides a cognitive management function in language use as well as in other cognitive activities. Thus Bachman clearly viewed oral competence as an interaction between the 
individual's ability and the context in which the individual was placed.

The work of these theoreticians continues to inform our understanding of oral competence among non-native English speakers. For example, Taguchi (2006) examined the speech acts of two disparate ability groups of Japanese college students with respect to "appropriateness" (sociolinguistic competence) and "linguistic expressions." Similarly, while Ting, Mahadhir, and Chang's (2010) study focused on appropriate use of grammatical expressions among Malaysian university students (linguistic competence) who were weak in English proficiency, the researchers did so within the context of a class on "English for Social Purposes." Other international theorists, including Lehmann (2007) from Germany, Jiang and Ting (2007) from China, and Cenoz and Gorter (2008) from the Basque Country, acknowledge the key roles these concepts of oral competence play in making sense of how people learn to speak English as an Additional Language. Indeed, as Celce- Murcia (2007) states (after having mentioned the contribution of Bachman to language assessment), "the model proposed by Canale and Swain (1980), along with the elaborations proposed by Canale (1983), remain the key sources for discussions of communicative competence and related applications in applied linguistics and language pedagogy" (p. 41). Collectively, these examinations of oral competence make a strong case that need to understand how individuals learn to speak English with respect to both their linguistic competence and their sociolinguistic competence before can decide on the best way of teaching them to speak English.

This knowledge is particularly important in the Philippines. Despite English being the medium of instruction for maths and sciences beginning at the primary school level (Kirkpatrick, 2009) and the widespread code-switching between Tagalog (the national language of the Philippines) and English, commonly known as Taglish (Metila, 2009), the English proficiency of Filipinos has been called into question (Bolton, 2008). As a result, attention has been directed toward finding better means of teaching English in the Philippines through probing students' language strategies, a concern that has encompassed recent research at the postsecondary sector (Asuncion, 2010; Querol, 2010). What also may prove of benefit to these investigations is a more thorough understanding of the levels, correlates, and characteristics of oral competence among post-secondary students in the Philippines, such as is provided by the current study.

\section{METHODS}

A mixed methods research design was used in this study. One hundred first-year students (72 male, 28 female) at a single college in a small city in the Philippines took part. Sixty-eight per cent of the students were aged 16-17 (the typical age for first-year college students); $64 \%$ had attended public schools. Approximately half (49\%) of the students had family incomes less than 10,000 pesos a month (approximately 230 US dollars). The students' English learning had taken place almost entirely at school with limited English material in their homes. Students were assessed individually by the lead researcher with responses audiotaped and then transcribed for analysis.

\subsection{Data Sources}

There were two tests of linguistic competence. The first focused on appropriate intonation patterns suited to the context of the passage, which contained eight (8) statements of varying and progressive lengths. The second required participants to read a 17-line poem that contained words in each line with similar morphology but divergent phonology (e.g., "sew" and "few").

As well, there was one test of sociolinguistic competence. Here students responded to questions about eight situations. For example, they were asked what they would do in the following hypothetical scenario: "You and John meet at a restaurant. He is not a friend but a classmate. You are going to have lunch with a friend you have not seen for a long time." Each of the tests was evaluated by three independent raters using a rubric for each item. For each rubric, a score of 4.20-5.00 represented an excellent level of competence, 3.40-4.19 a very good level of competence, 2.60-3.39 a moderate level of competence, 1.80-2.59 a poor level of competence, and 1.00-1.79 a minimal level of competence. Disagreements across raters were resolved through discussion until consensus was reached.

In addition to the ratings on the items, which determined levels of linguistic and sociolinguistic competence, test answers were correlated with demographic measures, obtained through self-report questionnaires. Finally, the lead researcher analyzed the error patterns on participant responses to all items to gain a sense of the characteristics of oral competence.

\section{RESULTS AND DISCUSSION}

\subsection{Levels of Oral Competence}

For the first linguistic test with its focus on intonation, average scores ranged from 2.67 to 3.45 with a weighted mean of 2.95. This result indicates that the respondents' intonation in oral communication in an English passage lacked the sameness of rise and fall of the voice at approximately the same syllables at similar circumstances typical to that of Standard American English.

One statement had an average score in the very good range (The fluency and intonation in natural but nonnative delivery was attributed to the fact that the respondents were second language learners of English 
and the features of their first language interfered in their acquisition of the second language.), while the rest were classified as moderate (exact terminology: "could speak at a deliberate pace, with some hesitation but using less sufficient intonation to convey meaning").

In contrast, the average scores on pronunciation ranged from 2.19 to 3.33 (weighted mean=2.48), with 5 of 17 rated as "moderate" and the rest as "poor" (exact terminology: "A somewhat frequent number of major and minor errors in pronunciation and fluency; skill demonstrated generally poorly"). In other words, the respondents' pronunciation and fluency had not achieved to the level of competence expected of a college student. Most of the common flaws in pronunciation occurred in the lack of discrimination of paired vowels, particularly short and long 'a, e, i, o, u' sounds. The regional accent common among Visayans is evident in the enunciation of vowels with consonants clusters where back vowels are more difficult to project than some front vowels. This result could be attributed to the absence of several variants of vowels and some consonants in the first language, which possibly had a negative interference in the production of lines in English.

Finally, for all but one of the eight statements (range: 2.51-3.21; weighted mean 2.90), students were judged as having a moderate level of sociolinguistic ability, meaning "there is some use of inappropriate linguistic forms for expressing the speech act." In this manner, the classroom situation may not have provided the pattern of communication that arose from situational contexts but instead structured thinking on the formal grammatical aspects of communication.

It is also possible that these students were not wellengaged in classroom activities where the integration of value statement components in communication lessons were contextualized in different situations like expressing apologies, compliments, requests, objections, and cooperation with each other. It is further possible that they had insufficient background in classroom interaction settings in the form of dialogues illustrating sociolinguistic competence in varied situations where students apologize, compliment, request, contradict, and the like.

However, it could be possible that they lacked listening and speaking sessions in interaction lessons providing them the opportunity to listen to a situation read in class or shown on video where they could speak out their thoughts as a reaction to the listening activity introduced in class. It is imperative that, in the teaching of foreign language today, language teachers have time for sociocultural teaching in an already time-limited curriculum. They should possess enough confidence in believing that they can teach the sociocultural aspects of foreign language learning well, and should well remember that the teaching of sociocultural competence often involves dealing with students' attitudes.

Collectively, these levels suggest that many students at this college, despite having approximately 10 years of schooling in English, were struggling with English oral competence, both linguistically and sociolinguistically. As such, the college needs to take measures to ensure that the English proficiency of its students is adequate for them to access the content taught in English in their subject-matter classes.

\subsection{Correlates of Oral Competence}

To examine the correlates of oral competence, students' results on the two linguistic tests were averaged. Then linguistic competence and sociolinguistic competence were correlated with age, gender, type of secondary school attended, and parental income. The plurality of males over females as subject-respondents could be contributory to these findings where the latter were noted to be much more inclined to verbal communication than the former.

Gender and parental income were both correlated with linguistic competence in that girls and students with higher parental income performed better than boys and students with lower parental income. Parents with minimal income may have experienced difficulty in acquiring English reading materials at home, which might affect their children's oral communication. In contrast, none of the four demographic variables predicted sociolinguistic competence. Thus the predictors of diverse factors of oral competence were themselves diverse.

\subsection{Characteristics of Oral Competence}

Three elements of statements affected the scores on the first linguistic test targeting intonation. First, length of sentence in number of words was directly related to the average score on the assessment of intonation. The longer the sentence, the more likely the student was to experience intonation problems. Second, stress marks in some individual words caused students difficulties, such as "discriminate," "uplifting," and "events," independent of the length of the sentence. Finally, commas in sentences consistently caused students to stumble with their intonation as they struggled with dependent clauses. Linguistic competence with respect to pronunciation scores were affected by number of contrasting words and by application of the same pronunciation rule to all the words in the line of poetry. In general, when there were three contrasting words, the students performed more poorly than when there were two contrasting words. With regard to application of the same rule to two contrasting words, an illustration is probably helpful. With the words "break" and "freak" (presented in that order), two types of error occurred. For some students, the long a sound in 
break was incorrectly applied to freak. For other students, their regional dialect interfered so that both words were pronounced with what might best be described as a short $\mathrm{i}$ sound. Interestingly, despite the general rule that, when two vowels occur together, the first vowel's long sound is correct, students did not generally pronounce break with a long e sound.

Sociolinguistic competence items, which were judged both for quality of expression and appropriateness, tended to contain two types of error related to the similarity of the situation with students' cultural backgrounds. For situations resonating with their own backgrounds, students had difficulty in not code-switching, perhaps not surprising given the wide-spread code-switching in the media and among younger persons in the Philippines. For situations divergent from their own backgrounds, students did not always give an answer that was appropriate for the context. The second type of error occurred much more frequently than the first type.

\section{CONCLUSION AND SCHOLARLY SIGNIFICANCE OF THE STUDY}

The Philippines with its ongoing commitment to teaching of English within the schools starting at the primary level is probably a leading-edge example of how students now learn in a media- saturated, globally accessible world. Filipino students are taught English from when they enter school, their media are often driven by English (as they watch movies in English, listen to English music, and read magazines and newspapers in Taglish), and their web-browsers commonly access the latest information about their own country in English (e.g., http://ph.yahoo.com).

Yet Filipino college students, at least in the college studied here, have ongoing struggles with the English language. By uncovering the sources of these struggles and by conducting similar studies with other populations, as researchers and teachers can find ways to reach these students and promote greater success in their English oral competence.

The author himself proposes a program of pedagogical intervention that will be applied in the school where he conducted the study through the four-year academic program across disciplines to develop a strong English Communication Program (ECP): (a) establish an assessment unit to promote different aspects of diagnosis, development of test materials, and research to provide data for instructional decisions; (b) establish the Reading Laboratory (RL) as a bridging and developing unit for the promotion of reading skills proficiency; (c) strengthen the English Immersion Program (EIP) to promote widespread use of the English language in all aspects of life in the campus; and (d) review the English program in general education and define the parameters of a language skills continuum that cuts across disciplines.

\section{ACKNOWLEDGMENT}

The paper reported herein was accepted and presented during the annual research conference initiated by the American Educational Research Association (AERA) held on April 13-17, 2012 in Vancouver, British Columbia, Canada. The author would like to thank the AERA International Relations Committee for honoring him the certificate and check as one of the International Travel Recipients. The author would also like to thank his editor and the assistance given by the Faculty of Education at Queen's University in Kingston, Ontario through the person of Dr. John G. Freeman, Queen's Director of Social Program Evaluation Group (SPEG).

\section{REFERENCES}

[1] Asuncion, Z. S. (2010). Filipino college freshman students' oral compensatory strategies. Philippine ESL Journal, 5, 2-21.

[2] Bachman, L. F. (1990). Fundamental considerations in language testing. Oxford, England: Oxford University Press.

[3] Bolton, K. (2008). English in Asia, Asian Englishes, and the issue of proficiency. English Today, 24(2), 312.

[4] Canale, M. (1983). From communicative competence to communicative language pedagogy. In J. C. Richards \& R. Schmidt (Eds.), Language and Communication (pp. 2-27). London, England: Longman.

[5] Canale, M., \& Swain, M. (1980). Theoretical bases of communicative approaches to second language teaching and testing. Applied Linguistics, 1, 1-47.

[6] Celce-Murcia, M. (2007). Rethinking the role of communicative competence in language testing. In E. A. Soler and M. P. S. Jordà (Eds.), Intercultural language use and language learning (pp. 41-57). Dordrecht, the Netherlands: Springer.

[7] Cenoz, J., \& Gorter, D. (2008). The linguistic landscape as an additional source of input in second language acquisition. International Review of Applied Linguistics (IRAL), 46, 267-287.

[8] Jiang, L., \& Duan, P. (2007). Interpretation of language competence and its enlightenment for TEFL. Sino-US English Teaching, 4(9), 29-34.

[9] Kirkpatrick, A. (2009). Learning English and other languages in multilingual settings: Myths and principles. Hong Kong, China: The Hong Kong Institute of Education.

[10] Lehmann, C. (2007). Linguistic competence: Theory and empiry. Folia Linguistica, 41, 223-278. 
[11] Metila, R. A. (2009). Decoding the switch: The functions of codeswitching in the classroom. Education Quarterly, 67, 44-61.

[12] Querol, M. B. (2010). College students' use of affective and social language learning strategies: A classroom-based research. Philippine ESL Journal, 5, 22-39.

[13] Taguchi, N. (2006). Analysis of appropriateness in a speech act of request in L2 English. Pragmatics, 16, 513-533.

[14] Ting, S.-H., Mahadhir, M., \& Chang, S.-L. (2010). Grammatical errors in spoken English of university students in oral communication course. GEMA OnlineTM Journal of Language Studies, 10(1), 5370. 